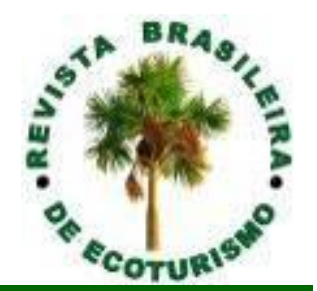

\title{
Monitoria ambiental e suas contribuições na gestão dos Parques Estaduais Caverna do Diabo, Ilha do Cardoso e Turístico do Alto Ribeira (Vale do Ribeira, SP)
}

\section{Local tourist guides and their contributions to the management of State Parks Caverna do Diabo, Ilha do Cardoso and Tourist of Alto Ribeira (Ribeira River Valley, SP, Brazil)}

\author{
Luciano Festa Mira, Maurício de Alcântara Marinho, Heros Augusto Santos Lobo
}

\begin{abstract}
RESUMO: A condução de visitantes em Unidades de Conservação no Estado de São Paulo é regulamentada desde 1998, com a chancela legal do profissional denominado como "monitor ambiental". A sua atuação se justificou, inicialmente, para preencher uma lacuna que o Estado não conseguia atender, de ter profissionais acompanhando visitantes em roteiros turísticos nos territórios sob sua gestão. Neste contexto, a monitoria ambiental ganhou força em regiões como o Vale do Ribeira, um território afetado por diversas áreas naturais protegidas e com precarização na oferta de empregos e oportunidades de geração de renda nos moldes da economia tradicional. A presente pesquisa foi desenvolvida no contexto de três Parques Estaduais da referida região e buscou avaliar a visão dos monitores ambientais sobre sua contribuição na gestão das Unidades de Conservação. Para tanto, foram feitas entrevistas com monitores ambientais, de modo a obter sua visão sobre sua atuação, tanto enquanto condutores de visitantes, como em outras atividades que porventura desenvolvam. Os resultados permitiram concluir que os monitores ambientais possuem uma compreensão clara sobre o significado teórico e prático de gestão participativa, bem como de sua ampla atuação e dos problemas desta relação com o Estado.
\end{abstract}

PALAVRAS CHAVE: Monitor Ambiental; Gestão Participativa; Unidade de Conservação; Ecoturismo.

ABSTRACT: The tourism in the natural protected areas in the State of São Paulo has been regulated since 1998, with the legal seal of the professional known as "monitor ambiental" (local tourist guide). Its performance was justified, initially, to fill a gap that the State could not meet, of having professionals accompanying visitors on tourist routes in the territories under its management. In this context, tourist guiding gained strength in regions such as Vale do Ribeira, a territory affected by several protected natural areas and with precariousness in the offer of jobs and income-generating opportunities. The present research was developed in the context of three State Parks in that region and sought to assess the vision of local tourist guides about their contribution to the management of the State Parks. For this purpose, interviews were conducted with local tourist guides, in order to obtain their vision of their performance, both as conductors of visitors and in other activities that they may develop. The results allowed us to conclude that the local tourist guides have a clear understanding of the theoretical and practical meaning of participatory management, as well as its wide performance and the problems of this relationship with the State.

KEYWORDS: Local Tourist Guide; Participatory Management; Natural Protected Areas; Ecotourism. 


\section{Introdução}

A condução de visitantes em roteiros de ecoturismo em áreas naturais protegidas é um dos importantes elementos que asseguram tanto a segurança, do ambiente e dos visitantes, quanto possibilita um acréscimo de qualidade na interpretação ambiental (BARBOSA; ZAMBONI, 2000; COUTINHO et al., 2014; GODINHO et al., 2015; MOREIRA, 2011). No Brasil, a atividade de condução é prevista por diversos diplomas públicos, resoluções e normativas, incluindo profissionais como guias de turismo, condutores de visitantes e monitores ambientais, entre outras denominações e especificações (SÃO PAULO, 1998, 2018; BRASIL, 2006; COUTINHO et al., 2014; GODINHO et al., 2016). O presente estudo se debruça sobre uma destas categorias, os monitores ambientais.

A monitoria ambiental foi desenvolvida na região do Vale do Ribeira, Estado de São Paulo, com o intuito de gerar oportunidades para os moradores do entorno das Unidades de Conservação (UCs) e atender a demanda de visitação turística. Esta concepção se assemelha a atuação dos condutores de visitantes em UCs, tendo como experiências pioneiras os condutores do Parque Nacional da Chapada dos Veadeiros, em 1981, e os monitores ambientais do Parque Estadual Turístico do Alto Ribeira (PETAR), em 1985 (MARINHO et al., 1987).

No entanto, os monitores ambientais tradicionalmente atuam em demandas ligadas à manutenção, conservação e gestão das UCs, expandindo a compreensão geral de serem condutores de turistas tão somente. Na porção paulista do Vale do Ribeira, existem UCs que protegem extensas áreas de Mata Atlântica, reconhecidas também pela biodiversidade e riqueza históricocultural como patrimônio da humanidade (UNESCO, 1999), e que apresenta forte vocação às práticas sustentáveis. A região conta hoje com a presença de monitores ambientais formados em todos os seus 22 municípios.

Neste contexto, o presente trabalho tem por objetivo avaliar a visão dos monitores ambientais sobre sua contribuição na gestão de três Parques Estaduais: Caverna do Diabo (PECD), Ilha do Cardoso (PEIC) e Turístico do Alto Ribeira (PETAR). Para tanto, foram desenvolvidos procedimentos de pesquisa com análises de dados secundários e entrevistas com monitores das UCs, visando levantar as atividades desenvolvidas, a compreensão sobre gestão participativa e o papel do monitor ambiental.

\section{Gestão participativa}

O termo "gestão participativa" é tradicionalmente utilizado em setores da sociedade como saúde e educação, conforme observado em mecanismos de busca de periódicos. Desde a Constituição Federal de 1988, no entanto, vem sendo ampliado e expandido para outras áreas da administração e gestão pública, em função da redemocratização e da conquista de direitos por parte da sociedade (ANDRADE, 2006; ANTUNES; BARRETTO, 2016). De acordo com Bobbio (2007), a alteração na passagem da democracia dos antigos à 
democracia dos modernos é a compreensão do modo como o povo irá participar no exercício ao direito a participação nas tomadas de decisões.

Para Loureiro (2004), o processo de educar vincula as esferas individuais às práticas coletivas, o que fornece aos sujeitos o significado de fazer parte da sociedade. É neste contexto que o autor aponta elementos que caracterizam o ideário de participação: compartilhar poder, respeitar o outro, assegurar igualdade na decisão e propiciar acesso justo aos bens socialmente produzidos. Afirma ainda que o ato de participação permite o exercício da autonomia com responsabilidade e de complementaridade entre as ações individuais e coletivas. É neste contexto que Sauvé (2005) e Salvatti e Consenza (2012) pontuam que o meio ambiente é um lugar de cooperação e de parceria para a realização de mudanças desejadas em prol da coletividade. Para tanto, é preciso aprender a discutir, argumentar e comunicar-se por meio de diálogos entre saberes científicos, de experiência e tradicionais

Levando-se em conta a legislação atual (BRASIL, 2000), todas as UCs devem promover a participação da sociedade nos processos de gestão. A participação se dá através dos Conselhos Gestores os quais, no geral, possuem caráter consultivo e são compostos por membros da sociedade civil e representantes das instituições governamentais. Este mecanismo permite a existência de um canal de participação da sociedade nos processos de tomadas de decisões. Particularizando para os casos estudados, nas três UCs abordadas verificou-se a existência dos Conselhos Consultivos e a efetiva participação dos Monitores Ambientais, seja de modo individual ou por meio da representatividade de Associações, comunidades ou lideranças comunitárias.

\section{Caracterização da área de pesquisa}

A área de abrangência do estudo é a região sul do estado de São Paulo, abrangendo a Bacia Hidrográfica do Rio Ribeira de Iguape e o Complexo Estuarino Lagunar de Iguape e Cananéia. Sua área de 2.830.666 hectares abriga uma população de 389.191 habitantes, compreendendo 22 municípios em São Paulo (IBGE, 2010). A região se destaca por pelo elevado grau de conservação de suas florestas e pela sua diversidade ecológica. Suas florestas equivalem a aproximadamente $22 \%$ dos remanescentes de Mata Atlântica existentes no Brasil, e abriga o maior contínuo do bioma. A região abriga além das florestas, importantes comunidades renascentes de indígenas, quilombolas, caiçaras e imigrantes que preservam suas respectivas culturas originárias. Apesar da sua valiosa grandeza em termos ambientais e culturais a região é historicamente uma das regiões mais pobres do Estado de São Paulo. Seus municípios possuem índices de desenvolvimento humano (IDH) inferiores as médias estaduais. Outros indicadores como: escolaridade, emprego e renda também são os mais baixos do Estado (IAC, 1990; MMA, 2010; RESENDE, 2011; SOUZA, 2017).

O Vale do Ribeira abriga em seu território grande número de UCs. A restrição territorial para o uso direto da terra, associada à dificuldade do relevo e às razões históricas da formação da região, culminaram em uma situação de menores possibilidades de emprego e renda para a população local, deixando- 
os à margem do desenvolvimento capitalista tradicional (IAC, 1990; SOUZA, 2017). Tais razões também fundamentam a importância dos programas de formação de monitores ambientais, como profissionais de um novo setor do mercado, voltado também para a conservação e para a sustentabilidade. $\mathrm{O}$ contexto das UCs englobados nesta pesquisa é ilustrado na Figura 1, com detalhamentos no Quadro 1.

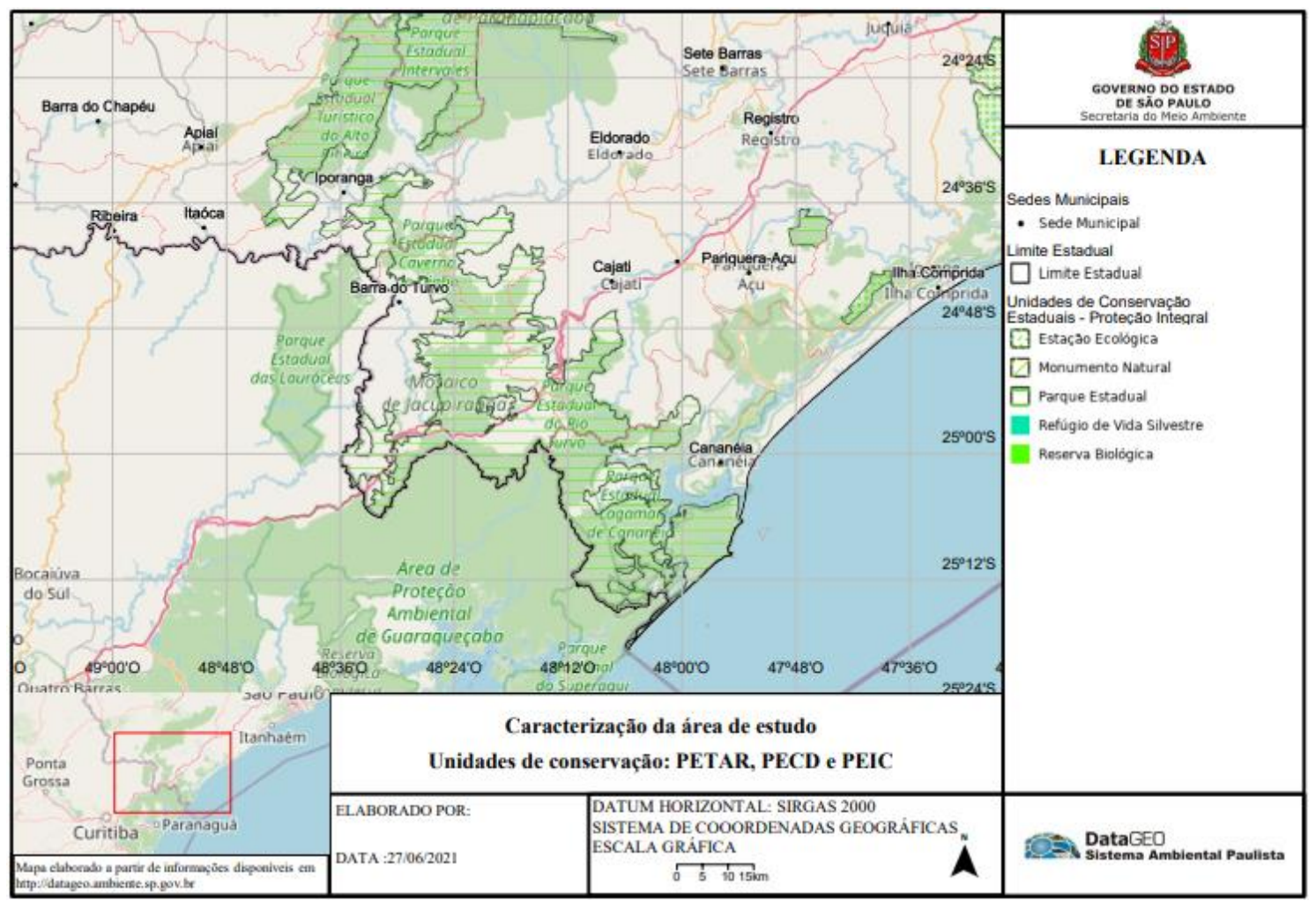

Figura 1: Localização das UCs pesquisadas.

Figure 1: Location of researched natural protected áreas.

Fonte: Elaborado pelo primeiro autor a partir de informações disponíveis em http://datageo.ambiente.sp.gov.br

Source: Prepared by the first author based on information available at http://datageo.ambiente.sp.gov.br

Quadro 1: Informações gerais das UCs pesquisadas.

Frame 1: General information of researched natural protected areas.

\begin{tabular}{|c|c|c|c|}
\hline $\begin{array}{l}\text { Unidade de } \\
\text { Conservação }\end{array}$ & Área total & Municípios & Plano de Manejo elaborado? \\
\hline $\begin{array}{l}\text { Parque Estadual Turístico } \\
\text { do Alto Ribeira - PETAR }\end{array}$ & $35.772,5$ ha & $\begin{array}{l}\text { Apiaí e } \\
\text { Iporanga }\end{array}$ & $\begin{array}{c}\text { Sim } \\
\frac{\text { https://www.infraestruturameioambie }}{\text { nte.sp.gov.br/fundacaoflorestal/plano }} \\
\frac{\text { s-de-manejo/planos-de-manejo- }}{\text { planos-concluidos/plano-de-manejo- }} \\
\text { pe-turistico-do-alto-ribeira-petar/ }\end{array}$ \\
\hline $\begin{array}{l}\text { Parque Estadual Caverna } \\
\text { do Diabo - PECD }\end{array}$ & $40.219,66$ ha & Eldorado & Não \\
\hline $\begin{array}{l}\text { Parque Estadual Ilha do } \\
\text { Cardoso - PEIC }\end{array}$ & $13.500,00$ ha & Cananeia & $\begin{array}{c}\text { Sim } \\
\frac{\text { https://smastr16.blob.core.windows.n }}{\frac{\text { et/fundacaoflorestal/2012/01/PlanoM }}{\text { anejo-PEIC.pdf }}} \\
\text { and }\end{array}$ \\
\hline
\end{tabular}


Estes parques foram selecionados devido ao fato de neles haver um maior número de monitores ambientais atuantes e capacitados, além de serem os Parques indutores da visitação no Vale do Ribeira. Cada um dos Parques destacados tem modus operandi gerenciais específicos, podendo o tipo e grau de participação dos monitores ambientais variarem entre eles. Esta seleção compõe uma extensa faixa territorial do Vale do Ribeira, abrangendo os munícipios do baixo, médio e alto Ribeira, o que foi intencionalmente considerado para anular vieses locais nos resultados.

\section{Etapas e procedimentos de pesquisa}

A pesquisa realizada, de caráter exploratório, partiu de dados secundários e avançou com a coleta de novos dados, por meio de formulários aplicados aos monitores. A pesquisa bibliográfica considerou a identificação e análise de artigos indexados em periódicos, atas de eventos científicos, monografias de pós-graduação, relatórios técnicos e documentos de diretrizes de organizações e outros eventos.

Já em relação à coleta de dados primários, foram adotados procedimentos para a obtenção das opiniões dos monitores ambientais, com a disponibilização de um formulário on line (Apêndice 1). Para a obtenção de uma amostra a mais ampla quanto possível, partiu-se de um universo de 50 monitores ambientais identificados por meio de redes sociais e contatados individualmente. O formulário foi enviado também para associações de monitores ambientais. Deste total, 12 retornaram a pesquisa com suas respostas.

A análise dos dados foi realizada de forma descritiva, com transcrição dos conteúdos apontados e tratamento anônimo das informações, de forma a preservar tanto o modo de se expressar quanto a identidade dos respondentes. Os conteúdos apontados foram analisados em função das bases teóricas compiladas e da trajetória profissional e de pesquisa dos autores, que atuam na região do Vale do Ribeira no contexto das UCs e da monitoria ambiental há pelo menos 20 anos.

\section{Resultados e discussão}

Do total de respondentes, 58\% eram do PETAR, 25\% do PEIC e $17 \%$ do PECD. Embora haja predominância dos respondentes do PETAR, a representatividade de monitores das outras duas UCs também deve ser considerada.

Inicialmente, são expostos os resultados das opiniões dos monitores ambientais sobre a sua percepção da atividade que exercem, ou seja, o que é a monitoria ambiental. Fazendo-se uma síntese das respostas, o monitor ambiental foi definido como:

- Educador ambiental.

- Guardião de riquezas naturais.

- A pessoa que recebe o turista e Ihe apresenta que se pode viver em harmonia com a natureza.

- Ética. 
- Agente multiplicador.

- Amor pela vida e natureza.

- Agente que liga as UCs às comunidades e ao governamental.

- Pessoa que possui conhecimento em relação ao ecossistema da região, que orientam e passam as informações do local. Um profissional preocupado com a conservação ambiental.

- Educador e gestor ambiental.

- Pessoa que está em contato com a natureza e, ao mesmo tempo, usufrui sem prejudicar.

- Intérprete tribal.

- Um Guia que fala e fala muito sobre tudo, em geral sobre o que lhe é familiar: o meio em que mora, a música que ouve os caminhos que andam, a comida que prefere etc.

Nota-se que as opiniões apontam para caminhos diversos, alguns mais focados em atividades exercidas - como a condução de visitantes - e outros focados em comportamentos - ex. guardião de riquezas naturais - e também em valores - ex. ética.

De um modo geral, o embasamento legal e a utilização da terminologia Monitor Ambiental começaram a ganhar força no Vale do Ribeira, posteriormente se consolidando com a criação da Resolução SMA n. 32 de 31 de Março de 1998. Esta resolução foi atualizada e passou a ser regulamentada pela Resolução SMA195/2018 de 21 de dezembro de 2018. Em linhas gerais, a monitoria ambiental nesta última resolução está descrita da seguinte maneira:

Atividade relacionada ao uso público nas áreas sob gestão da Secretaria de Estado do Meio Ambiente e em seu entorno, incluindo atividades informativas, interpretativas e educativas sobre o ambiente natural e cultural (SÃO PAULO, 2018, p.2).

Além disso, esse diploma público define o monitor ambiental como:

Pessoa capacitada a exercer a atividade de monitoria ambiental, designada ou autorizada pelo órgão que o cadastrou nas áreas sob gestão da Secretaria de Estado do Meio Ambiente e entidades vinculadas, conduzindo visitantes e contribuindo para a sensibilização e aprendizagem deste público, para sua segurança e para a minimização e monitoramento dos impactos advindos das atividades de uso público, de acordo com as diretrizes e normas desta Resolução e das editadas pelo órgão gestor em que se cadastrou (SÃO PAULO, 2018, p.2).

Conforme acrescenta Torres (2008, p. 42) a monitoria ambiental "tem em seu papel o intuito de geração de oportunidades econômicas para os moradores de entorno das Unidades de Conservação através do desenvolvimento de atividades ecoturísticas". Coutinho et al. (2014) amplia este escopo, pontuando que os monitores ambientais são agentes 
fundamentais para a conservação dos ambientes naturais. Afirma ainda que guias, monitores ambientais e condutores são muito importantes na interpretação do ambiente, ajudando na tradução ou explicação dos processos da natureza e sua interação com o ser humano estimulando e valorizando a cultura local. Esta lógica corrobora a linha definida por Tilden (2007), sobre a interpretação dirigida e a possibilidade de aumento da interação entre os visitantes e o meio visitado.

Este desdobramento lógico apontado por Coutinho et al. (2014), sobre o papel do monitor ambiental para a conservação ambiental, acrescido da lógica do desenvolvimento local presente em Torres (2008), também foram questionados. Em sua opinião, a monitoria ambiental contribui para estes aspectos da seguinte forma:

- Sem monitoria não há preservação, fiscalização.

- Acredito que o monitor exerce papel relevante na conservação ambiental, porém faltam capacitação e domínio de conhecimento (visão global) para ser agente de desenvolvimento local.

- A monitoria auxilia o desenvolvimento local, ajudando a cuidar, ensinando, passando informações aos grupos visitantes e às famílias que vivem no entorno do Parque.

- Importante e ao mesmo tempo desvalorizada, só vou acreditar que o monitor ambiental tem o seu valor quando passar a ser um profissional reconhecido na carteira.

- No ponto de vista da conservação ambiental o monitor ambiental é a pessoa que leva informações ao viajante, informações essas sobre a região e da importância da preservação e conservação do mesmo. Já pelo ponto de vista do desenvolvimento local, é mais importante ainda, pois muitos guias deixaram de ser mateiros, palmiteiros para ser monitores ambientais e com isso ter uma renda extra.

- Base da renda de muitas famílias que se encontram no local.

- A preservação ambiental vai muito além do que cuidar, pois somente cuidamos daquilo que conhecemos e damos valor, o monitor ambiental tem essa missão, fazer a ligação entre cultura, a natureza e as pessoas que vivem foram desse ambiente.

- Com a monitoria ambiental trouxe muitos benefícios para a comunidade local, melhoria na infraestrutura, desenvolvimento pra toda a comunidade e com isso consequentemente ajudamos a preservar, cuidar da UC.

- Ter seu reconhecimento e valores reconhecidos.

- Ajuda na preservação e fomenta o desenvolvimento das UCs.

- A monitoria é importante na conservação dos atrativos e trilhas de acesso, realizando manutenção periódica e orientando os visitantes sobre comportamentos e limitando o acesso de suporte de cada atrativo, e promovendo o turismo de base comunitária, gerando renda as comunidades, dono de pousadas e restaurantes, pescadores e outros.

- Os monitores por terem mais contato com o uso público, é o agente que acaba controlando as ações invasivas e informando sobre os regramentos da UC.

Percebe-se que alguns respondentes focaram na descrição de atividades desenvolvidas, e não em sua contribuição para a conservação ambiental e desenvolvimento local. Outros, no entanto, apontaram que a monitoria ambiental contribui para tais papeis, algo já pontuado anteriormente 
nos trabalhos de Castro e Espinha (2008), Severian et al. (2014) e Godinho et al. (2016).

Cabe ressaltar que $58 \%$ dos respondentes tenham afirmado que participam do conselho gestor das UCs em que atuam. No entanto, apenas uma menção indireta (agente que liga as UCs às comunidades e ao governamental) foi feita quando perguntado sobre a atuação dos monitores. A análise das diretrizes apontadas por Brasil (2000) e o estudo de Salvatti e Consenza (2012), permitem compreender que a atuação junto aos conselhos gestores é uma ação de gestão participativa, a qual se comprova como sendo exercida, de forma representativa, pelos monitores ambientais. Embora não tenham mencionado, a priori, a atuação na gestão participativa como sendo uma das atividades dos monitores ambientais, nota-se que os respondentes possuem uma noção clara sobre o tema e sobre as possibilidades de atuação, por meio de suas respostas para a questão sobre o significado da gestão participativa:

- Gestão que integra os demais na sua administração, que é acessível a opiniões e está sempre buscando melhorias para funcionários, colaboradores e visitantes.

- É a participação de diferentes públicos (diretos e indiretos) nas tomadas de decisão.

- A união de todos por um bem comum. Participamos de decisões, no que se refere ao desenvolvimento e à proteção ambiental.

- Entendendo que educação ambiental promove a transformação social inspirada no diálogo, no exercício da cidadania, no fortalecimento dos sujeitos e criação de espaços coletivos de atuação.

- Gestão participativa é uma parceria entre o Parque e o guia local onde cada um faz sua parte, facilitando assim o bom andamento do trabalho, tanto da gestão vigente quanto do monitor ambiental e das agências receptivas da cidade.

- Onde comunidade tem direito, decide e opina sobre o caminho e rumo que a UC deva tomar.

- Um Sistema de Gestão onde a comunidade participa ativamente com o Estado na gestão de problemas e administrativas.

- Entendo que todos os participantes ou envolvidos possam dar suas opiniões pra melhorar seu ambiente de trabalho.

- Interligação de diferentes atores da sociedade.

- Resolver os interesses comunitários.

- Envolvimento do poder público, sociedade civil representativa, comunidades, e gestão das UCs em decidir sobre atividades e outros assuntos dentro das UCs.

- A gestão da Unidade se dá por representantes de vários órgãos - públicos, privados, ongs etc., em reuniões, para opinarem ou deliberarem assuntos importantes. Os assuntos podem ser os mais variados, atendendo as comunidades, a compatibilidade destas com a conservação etc.

Além de se posicionarem sobre o significado do termo, também foi questionado sobre a opinião dos monitores ambientais sobre: a importância da gestão participativa em sua relação com as UCs, exemplos de instrumentos para a gestão participativa; e ações desenvolvidas pelos monitores que contribuam com a gestão da UC. Os resultados são descritos no Quadro 2. 
Quadro 2: Importância, instrumentos e exemplos para a gestão participativa dos monitores ambientais nas UCs

Frame 2: Importance, instruments and examples for the participatory management of local tourist guides in natural protected areas

\begin{tabular}{|c|c|c|}
\hline $\begin{array}{c}\text { Importância da gestão participativa para as } \\
\text { UCs }\end{array}$ & Instrumentos para a gestão participativa & $\begin{array}{c}\text { Atividades desenvolvidas por monitores } \\
\text { ambientais que contribuem para a gestão da UC }\end{array}$ \\
\hline $\begin{array}{l}\text { Primordial, pois é através da gestão que há um } \\
\text { turismo sustentável. }\end{array}$ & Cursos de capacitação. & $\begin{array}{l}\text { Ajuda em manutenção de trilhas, conservação dos } \\
\text { atrativos. }\end{array}$ \\
\hline $\begin{array}{l}\text { Extremamente interessantes, pois envolve } \\
\text { diversos interesses. }\end{array}$ & $\begin{array}{l}\text { Conselhos, consultas públicas, câmaras } \\
\text { temáticas. }\end{array}$ & $\begin{array}{l}\text { Treinamentos, manutenção, decisão sobre visitação e } \\
\text { roteiros, divulgação e Educação Ambiental. }\end{array}$ \\
\hline $\begin{array}{l}\text { Somos todos participantes nas decisões e } \\
\text { trabalhando para que o Parque venha a crescer e } \\
\text { melhorar sempre, pensando principalmente nas } \\
\text { gerações futuras. }\end{array}$ & Reuniões, pesquisas, decisões etc. & $\begin{array}{l}\text { Limpezas e manutenções voluntárias, palestras com } \\
\text { alguns desses monitores. }\end{array}$ \\
\hline $\begin{array}{l}\text { Fortalecimento dos sujeitos e criação de espaços } \\
\text { coletivos, moradores passaram a atuar como } \\
\text { agentes de preservação, monitorando e } \\
\text { denunciando o descarte de lixo e entulho e as } \\
\text { ações ilegais que ocorriam no Parque, como a } \\
\text { caça e ações criminosas. }\end{array}$ & $\begin{array}{l}\text { Ações de conscientização sobre o descarte de } \\
\text { lixo e entulho; Apoio da comunidade à } \\
\text { vigilância. Ações educativas com crianças do } \\
\text { programa Escola da Família. }\end{array}$ & $\begin{array}{l}\text { Com a terceira idade, um trabalho feito para que os } \\
\text { moradores mais antigos que ainda relatam histórias e } \\
\text { acontecimentos relacionados a caverna quebrando o } \\
\text { tabu mostrando a realidade e esse mundo } \\
\text { maravilhoso que temos a oferecer. Tudo é possível } \\
\text { não há idade pra ser amante de cavernas. Fantástico. }\end{array}$ \\
\hline $\begin{array}{l}\hat{E} \text { de suma, pois sem a colaboração de ambas as } \\
\text { partes, fica difícil ter uma boa convivência de } \\
\text { trabalho e um bom desenvolvimento das } \\
\text { atividades. }\end{array}$ & $\begin{array}{l}\text { Um bom plano de manejo do local é um ótimo } \\
\text { instrumento para gestão participativa. }\end{array}$ & $\begin{array}{l}\text { Uma das atividades que acontece no PECD são } \\
\text { algumas datas comemorativas como dia da água, dia } \\
\text { do morcego, dia do meio ambiente dentre outras } \\
\text { ações que são feitas em conjunto com os monitores } \\
\text { locais. }\end{array}$ \\
\hline $\begin{array}{l}\text { Muito importante para que a comunidade possa } \\
\text { dar norte para UC e que comunidade tenha um } \\
\text { Turismo sustentável e preservação da UC. }\end{array}$ & Conselho construtivo do Parque. & Manutenção da UC com serviços voluntários. \\
\hline $\begin{array}{l}\text { Somente a sociedade diretamente envolvida nas } \\
\text { UCs pode detectar problemas e muitas vezes } \\
\text { somente ele tem a solução pra esses problemas. }\end{array}$ & $\begin{array}{l}\text { Coopervales, Intervales, Parque Caverna do } \\
\text { Diabo. }\end{array}$ & $\begin{array}{l}\text { O controle de visitação em UCs, a análise e avaliação } \\
\text { das normas implantadas pela diretoria das UCs, } \\
\text { acompanhamento de pesquisas de longo prazo. }\end{array}$ \\
\hline $\begin{array}{l}\text { Com a gestão participativa pode haver mudanças } \\
\text { e melhorias e assim um desenvolvimento na } \\
\text { participação de todos, obtendo ótimos resultados. }\end{array}$ & $\begin{array}{l}\text { Envolver a comunidade na tomada de decisões, } \\
\text { capacitação. }\end{array}$ & $\begin{array}{l}\text { Limpeza das trilhas são feitas por mutirão pelos } \\
\text { monitores. }\end{array}$ \\
\hline
\end{tabular}


...continuação.

\begin{tabular}{|l|l|l|}
\hline \multicolumn{1}{|c|}{$\begin{array}{c}\text { Importânço da gestão participativa para as } \\
\text { UCs }\end{array}$} & Instrumentos para a gestão participativa & $\begin{array}{l}\text { Atividades desenvolvidas por monitores } \\
\text { ambientais que contribuem para a gestão da UC }\end{array}$ \\
\hline $\begin{array}{l}\text { Colaboração e integração de um bem comum } \\
\text { com todos e para todos. }\end{array}$ & Participação no conselho gestor. & $\begin{array}{l}\text { Mutirão de limpeza e roçadas em trilhas, } \\
\text { mapeamento de roteiros, divulgação da UC, } \\
\text { acompanhamento de pesquisadores de diversas } \\
\text { áreas, acompanhamento de visitantes. }\end{array}$ \\
\hline $\begin{array}{l}\text { A importância é que ajuda a resolver problemas } \\
\text { que ajudam tanto as comunidades e o meio. }\end{array}$ & Ser participativo nas demandas. \\
\hline $\begin{array}{l}\text { Envolvimento de todos os atores representativos } \\
\text { para tomar decisões de preservação e respeitar } \\
\text { os modos de vida dos locais. }\end{array}$ & Reunião de conselho das Unidades. \\
praias.
\end{tabular}


De um modo geral, nota-se uma consonância entre a visão dos monitores sobre a importância da gestão participativa para as UCs e o SNUC (BRASIL, 2000), bem como em relação a aspectos pontuados em estudos como os de Andrade (2006) e Antunes e Barreto (2016). Quanto aos instrumentos de gestão, predominam elementos previstos em Brasil (2000) - conselho gestor, plano de manejo e consultas públicas - e outras ações práticas diretas, evidenciando tanto o âmbito decisório quanto a execução de atividades. $\mathrm{O}$ aspecto prático fica mais evidente nos exemplos de atividades desenvolvidas, nas quais predominam ações de conscientização e manutenção, não somente de aspectos e elementos voltados para o uso público, mas da totalidade da UC. Em meio a estas relações de atuação junto as UCs, emergem também dificuldades, como as apontadas pelos respondentes:

- Falta de verbas para manutenção de atrativos.

- Hierarquizar as demandas, condução e produtividade sobre as questões.

- Algumas pessoas, vendo suas ideias demorar a surtir efeitos, muitas vezes se desanimam e começam a se sentir inúteis.

- É você ser ouvido, nos tornamos refém da UC. A última palavra sempre será a de uma unidade de conservação.

- Quando só beneficia uma das partes. Quando não se cumpre regras de trabalho. Quando não se trabalha com ética e responsabilidade.

- Falta de continuidade.

- Fazer com que o poder público entenda a importância, pois as comunidades estão perdendo seu espaço.

- Infelizmente não são todos os participantes/monitores que são mais participativos, não são todos que respeitam as regras impostas pelo parque. $\mathrm{E}$ o não cumprimento das punições quando alguém não respeita essas regras.

- As responsabilidades de cada ator envolvido.

- Alguns assuntos as vezes não são resolvidos.

- Não abrange as necessidades e dados real de uma unidade de conservação, somente visando benefícios para poucos.

- Eu acho que muita gente ainda espera muito do Estado, e infelizmente não podemos mais contar tanto. As vezes a espera sem retorno gera frustração e frustração gera abandono das reuniões e atividades.

Em relação aos entraves, estes podem ser agrupados em temas mais gerais, como a falta de espaço individual e coletivo para o posicionamento de ideias, a quebra de continuidade de ações - característica comum do poder público no Brasil e a mudança de atitudes por parte das pessoas; e em outros temas já reportados em pesquisas anteriores, como a menção à precarização proposital do Estado (REIS; QUEIROZ, 2017) e a existência de privilégios para determinados grupos (BORSANELLI; LOBO, 2013).

Por fim, sintetizando os dados analisados, foram identificadas diversas formas de atuação dos monitores ambientais no apoio à gestão das UCs, caracterizando e evidenciando a existência de gestão participativa:

- Manutenções de trilhas;

- Conservação e manutenção dos atrativos;

- Participação e realização de treinamentos;

- Decisões conjuntas sobre visitação e roteiros;

- Promoção e divulgação sobre Educação Ambiental; 
- Limpezas e manutenções voluntárias;

- Apoio e organização de eventos locais;

- Controle de visitação;

- Mutirões de limpeza e roçada;

- Informações e orientações aos visitantes;

- Participações em reuniões;

- Participações nos Conselhos Consultivos.

Observa-se com isso, que a gama de participação do monitor ambiental na gestão das UCs vai além da condução de visitantes. Sua atuação culmina por suprir a deficiência do conhecido quadro precário de recursos humanos estabelecido nas UCs (REIS; QUEIROZ, 2017). Desta forma, nota-se por um lado a geração de oportunidades para as comunidades locais e, por outro, o comodismo do Estado em relação a problemas das UCs que deveriam receber mais atenção do órgão gestor conforme estabelecido em Brasil (2000) - para resolução direta, ao invés do uso de parcerias ou até mesmo da omissão sistemática e intencional, em alguns casos.

\section{Considerações finais}

O presente estudo demonstrou a importância e a função do monitor ambiental para a gestão das UCs investigadas. Trata-se de um profissional que atua na linha de frente, uma vez que ele acaba sendo o elemento humano que se representa a UC para o público. O monitor também é responsável pela disseminação dos princípios da conservação, por meio de seu atendimento ao público, atendendo aos princípios legais federais (BRASIL, 2000) e estaduais (SÃO PAULO, 2018).

Quanto ao pressuposto inicial neste trabalho, conforme demonstrado nos dados obtidos, o monitor ambiental desempenha comprovadamente papel fundamental para a gestão da UC, atuando em diversas frentes e níveis de gestão e participação em atividades, muitas delas, descoladas da premissa de criação do papel do monitor, que é o uso público. Neste sentido, o monitor ambiental é um protagonista social. É um ator com potencial transformador da sociedade devido a sua atuação, tanto local, quanto pelos conhecimentos disseminados em seu trabalho de educação e interpretação ambiental.

Este estudo possibilitou observar a transformação do papel do monitor ambiental, que inicialmente surgiu em um contexto de inclusão social, como mero coadjuvante, para o papel de protagonista na conservação ambiental. A sua atividade não é somente a condução de grupos de visitantes, pois está atrelada a implantação de políticas públicas ambientais, educacionais e mudanças de paradigmas sociais. Assim, refere-se ao exercício da cidadania. O monitor ambiental internalizou a UC em seu modo de vida, demonstrando cuidados e preocupações com a gestão de seus territórios. Porém, questionamentos advêm desta relação: a recíproca existe? Até que ponto?

Espera-se, por fim, que este trabalho permita suscitar reflexões e mesmo mudanças nas práticas entre monitores ambientais e UCs, fortalecendo a atividade desempenhada pelos monitores ambientais e o reconhecimento de sua amplitude de atuação. 


\section{Referências}

ANDRADE, J.A. Redes de Atores: Uma nova forma de gestão das políticas públicas no Brasil. Gestão \& Regionalidade, n 64, p.52-66, 2006.

ANTUNES, E.; BARRETTO, S.F. Administração Pública e Gestão Participativa de Programas de Políticas Públicas. Juridicidade e Estratégias de Gestão: Uma Experiência no Programa EDPOPSUS. Revista de Direito da Cidade. Vol. 8, n. 4, p. 1423- 1441.

BARBOSA M.A.C.; ZAMBONI, R.A. Formação de um cluster em torno do turismo de natureza sustentável em Bonito. Brasília: IPEA/CEPAL, 2000.

BOBBIO, N. Do fascismo à democracia: os regimes, as ideologias, os personagens e as culturas políticas. Rio de Janeiro: Elsevier, 2007.

BORSANELLI, F.A.; LOBO, H.A.S. Percepções dos visitantes sobre a evolução do espeleoturismo no PETAR face ao fechamento das cavernas turísticas em 2008. In: RASTEIRO, M.A.; MORATO, L. (orgs.) Congresso Brasileiro de Espeleologia, 32, 2013. Barreiras. Anais. Campinas: SBE, 2013. p.45-54. Disponível em: $<$ http://www.cavernas.org.br/anais32cbe/32cbe 045-054.pdf>. Acesso em: 2.jul.2021.

BRASIL. Lei Federal № 9.985, de 18 de julho de 2000. Regulamenta o art. 225, § 10, incisos I, II, III e VII da Constituição Federal, institui o Sistema Nacional de Unidades de Conservação da Natureza e dá outras providências. Disponível em: http://www.planalto.gov.br/ccivil 03/leis/19985.htm acesso em 27/06/2021.

CASTRO, C.E.; ESPINHA, A.M.L. Narrativas sobre a efetivação de um parque e algumas de suas humanidades. Pesquisas em Turismo e Paisagens Cársticas, v.1, n.1, p.7-17, 2008.

COUTINHO, M. P. C.; PEREIRA, P. R.; SETTE, I. R. O Relato da Experiência dos Cursos de Espeleoturismo para Guias e Condutores na Região da Bacia do São Francisco. Brasília: Editora IABS, 2014. 92 p.

GODINHO, L.P.S.; LENHARE, B.D.; BARIONI, A.; et al. Cursos de capacitação em Geologia para os monitores ambientais do Parque Estadual Turístico do Alto Ribeira (PETAR): uma análise de 10 anos de atuação do GGEO. Pesquisas em Turismo e Paisagens Cársticas, Campinas, vol. 9, n. 1, p. 53-62, 2016.

INSTITUTO AGRONÔMICO DE CAMPINAS (IAC). Macrozoneamento das Terras da Região do Rio Ribeira de Iguape. Campinas, 1990.

IBGE - 2010 fonte: https://www.ibge.gov.br/ acesso 24/08/2020

LOUREIRO, C.F.B. Educar, participar e transformar em educação ambiental. Revista Brasileira de Educação Ambiental. v.1, p.13-20, 2004.

MARINHO, M.A. et al. A Formação de Monitores Ambientais: Estratégia para a Conservação e o Desenvolvimento Sustentável junto as Comunidades Vizinhas ao PETAR (Parque Estadual Turístico do Alto Ribeira). In: Congresso Brasileiro de Unidades de Conservação, 1., 1997, Curitiba, PR. Anais [...] vol. II, p. 405-418. Curitiba: IAP: UNILIVRE: Rede Nacional Pró Unidades de Conservação, 1997.

MINISTÉRIO DO MEIO AMBIENTE (MMA) Mata Atlântica: patrimônio nacional dos brasileiros. Secretaria de Biodiversidade e Florestas. Núcleo Mata Atlântica e Pampa. Brasília: MMA, 2010. 
MOREIRA, J.C. Geoturismo e interpretação ambiental. Ponta Grossa: UEPG, 2011. $157 \mathrm{p}$.

REIS, A.F.; QUEIROZ, O.T.M.M. Concessões nas Unidades de Conservação do Estado de São Paulo: reflexões, oportunidades e desafios. Revista Brasileira de Ecoturismo, v.10, n.2, pp.376-387, 2017.

RESENDE, R.U. Plano territorial de desenvolvimento rural sustentável Território Vale do Ribeira (SP). Brasília: MDA, 2011.

SALVATI, P.G.S.; COSENZA, A. Compreendendo a formação ecológica de monitores ambientais: o caso do Projeto 'Monitores Ambientais de Recursos Hídricos'. Pesquisa em Educação Ambiental, vol. 7, n.1, p. 139-153, 2012.

SÃO PAULO (Estado). Secretaria do Meio Ambiente. Resolução SMA n.32 de 31 de março de $1998 . \quad$ Disponível em: https://smastr16.blob.core.windows.net/legislacao/2016/12/RESOLUCAO-SMA-3231031998.pdf. Acesso em 10 mar. 2020.

SÃO PAULO (Estado). Secretaria do Meio Ambiente. Resolução SMA n.195 de 21 de dezembro de 2018.2 Disponível em: https://www.infraestruturameioambiente.sp.gov.br/legislacao/2018/12/resolucaosma-195-2018/. Acesso em: 8 ago. 2020.

SÃO PAULO (Estado). Infraestrutura de dados espaciais ambientais do Estado de São Paulo - IDEA-SP - DATAGEO - Sistema ambiental paulista Base territorial Ambiental Unificada - 2021 disponível em: http://datageo.ambiente.sp.gov.br

SAUVÉ, L. Educação Ambiental: possibilidades e limitações. Educação e Pesquisa, v. 31, n. 2, p.317-322, mai/ago. 2005.

SEVERIAN, B.A.; ABRANTES, G.; LOPEZ-RICHARD, V. Capacitação e treinamento para gestão de atividades de campo em Unidades de Conservação: avaliação do projeto e seu impacto na evolução dos guias e monitores. In: $22^{\circ}$ Congresso de Iniciação Científica, 2014, São Carlos. Anais de Eventos da UFSCar, 2014. v. 10.

SOUZA, P.B. Direitos, comunidades quilombolas e conservação da biodiversidade: 0 exemplo do Vale do Ribeira/SP. 2017.197 p. Tese (Doutorado em Direito Político e Econômico) - Universidade Presbiteriana Mackenzie, São Paulo-SP, 2017.

TILDEN, F. Interpreting our Heritage. 4a ed., ex ed. Chapel Hill, EUA: Editora da Universidade da Carolina do Norte, 2007.

TORRES, E.M.G. Percepções de um grupo de guias e monitores ambientais sobre o ambiente em que atuam (Paraty-RJ). Educação Ambiental BE-597, vol. 1, p. 49-75, 2008.

UNESCO. Atlantic forest south-east reserves. Paris: Unesco, 1999. Disponível em: <http://whc.unesco.org/en/list/893>. Acesso em: 15 Fev. 2018. 
Luciano Festa Mira: Universidade Federal de São Carlos, Sorocaba, SP, Brasil.

E-mail: lucianofestamira@yahoo.com.br

Link para curriculum lattes: http://lattes.cnpq.br/7494234531879413

Maurício de Alcântara Marinho: Universidade Federal de São Carlos, Sorocaba, SP, Brasil.

E-mail: mauricioamarinho@gmail.com

Link para curriculum lattes: http://lattes.cnpq.br/2710377857519929

Heros Augusto Santos Lobo: Universidade Federal de São Carlos, Sorocaba, SP, Brasil.

E-mail: heroslobo@ufscar.br

Link para curriculum lattes: http://lattes.cnpq.br/9405961078398915 


\section{APÊNDICE 1 - FORMULÁRIO DE PESQUISA}

1. O que você entende por gestão participativa em Unidades de Conservação?

2. Qual a importância da gestão participativa da Unidade de Conservação?

3. Cite exemplo de instrumentos para a gestão participativa.

4. Como você vê o papel do monitor ambiental no processo de apoio a gestão da Unidade de Conservação? Cite exemplos.

5. Aponte as Dificuldades na Gestão Participativa e Implantação da Unidade de Conservação.

6. Qual sua visão sobre a Monitoria Ambiental do ponto de vista do conservação ambiental e desenvolvimento local?

7. Cite Atividades que são desenvolvidas ou que tenham contribuições da Monitoria ambiental para a gestão da Unidade de Conservação. Descreva-as.

8. Em uma escala de 1 a 5 ( Onde $1=$ Minima e $5=$ Máxima) como você avalia a importância da Monitoria Ambiental no apoio à gestão da Unidade de Conservação.

9. Qual a Importância do trabalho da Monitor Ambiental para a gestão da Unidade de Conservação?

10. Você desenvolve outra atividade remunerada além da Monitoria Ambiental?

11. Você se considera um educador ambiental?

12. Você conhece a Politica Nacional de Educação Ambiental?

13. Você participa do Conselho Gestor da Unidade de Conservação?

14. Você possui cadastro na Unidade de Conservação?

15. O que significa para você ser Monitor Ambiental?

16. Para você qual é a definição de Monitor Ambiental?

17. Como você avalia seus conhecimentos sobre:

\begin{tabular}{|l|l|l|l|l|}
\hline Leis/Normas & Não conheço & $\begin{array}{l}\text { Conheço } \\
\text { pouco }\end{array}$ & Conheço & $\begin{array}{l}\text { Conheço } \\
\text { Bem }\end{array}$ \\
\hline Constituição Federal & & & & \\
\hline Resolução SMA 32/1998 & & & & \\
\hline $\begin{array}{l}\text { Politica Nacional de Educação } \\
\text { Ambiental LEI No 9.795, DE 27 } \\
\text { DE ABRIL DE 1999 }\end{array}$ & & & & \\
\hline $\begin{array}{l}\text { Plano de Manejo da sua } \\
\text { Unidade de Conservação }\end{array}$ & & & & \\
\hline $\begin{array}{l}\text { Sistema Nacional de Unidades } \\
\text { de Conservação }\end{array}$ & & & & \\
\hline
\end{tabular}

18. Você faz parte de alguma Associação, ONG ou Empresa?

19. Qual foi a Instituição realizadora do Curso?

20. Qual sua escolaridade?

21. Há quanto tempo atua como monitor ambiental?

22. Unidades de Conservação em que atuam como Monitor Ambiental e participaram da pesquisa. 